\title{
A retrospective cohort study of U.S. service members returning from Afghanistan and Iraq: is physical health worsening over time?
}

\author{
Michael J Falvo ${ }^{1,2^{*}}$, Jorge M Serrador ${ }^{1,3,4,5,6,7}$, Lisa M McAndrew ${ }^{1,8}$, Helena K Chandler ${ }^{1}$, Shou-En Lu ${ }^{9}$ \\ and Karen S Quigley ${ }^{10,11}$
}

\begin{abstract}
Background: High rates of mental health disorders have been reported in veterans returning from deployment to Afghanistan (Operation Enduring Freedom: OEF) and Iraq (Operation Iraqi Freedom: OIF); however, less is known about physical health functioning and its temporal course post-deployment. Therefore, our goal is to study physical health functioning in OEF/OIF veterans after deployment.

Methods: We analyzed self-reported physical health functioning as physical component summary (PCS) scores on the Veterans version of the Short Form 36 health survey in 679 OEF/OIF veterans clinically evaluated at a post-deployment health clinic. Veterans were stratified into four groups based on time post-deployment: (1Yr) 0 - 365 days; (2Yr) 366 - 730 days; (3Yr) 731 - 1095 days; and (4Yr+) > 1095 days. To assess the possibility that our effect was specific to a treatment-seeking sample, we also analyzed PCS scores from a separate military community sample of 768 OEF/OIF veterans evaluated pre-deployment and up to one-year post-deployment.

Results: In veterans evaluated at our clinic, we observed significantly lower PCS scores as time post-deployment increased $(p=0.018)$ after adjusting for probable post-traumatic stress disorder (PTSD). We similarly observed in our community sample that PCS scores were lower both immediately after and one year after return from deployment ( $p<0.001)$ relative to pre-deployment PCS. Further, PCS scores obtained 1-year post-deployment were significantly lower than scores obtained immediately post-deployment $(p=0.02)$.

Conclusion: In our clinical sample, the longer the duration between return from deployment and their visit to our clinic, the worse the Veteran's physical health even after adjusting for PTSD. Additionally, a decline is also present in a military community sample of OEF/OIF veterans. These data suggest that, as time since deployment length increases, physical health may deteriorate for some veterans.
\end{abstract}

Keywords: Veterans, Military personnel, Veterans health, Quality of life, Operation enduring freedom, Operation iraqi freedom, Health surveys

\section{Background}

Prior to deployment to Afghanistan and Iraq in support of Operations Enduring and Iraqi Freedom (OEF/OIF), US service members report baseline health functioning superior to that of the general US population [1]. Following deployment, however, veterans report they have poorer

\footnotetext{
* Correspondence: Michael.Falvo@va.gov

${ }^{1}$ War Related IIIness and Injury Study Center, Department of Veterans Affairs New Jersey Health Care System, 385 Tremont Ave, East Orange, NJ, USA

${ }^{2}$ Department of Physical Medicine and Rehabilitation, New Jersey Medical School - University of Medicine and Dentistry of New Jersey, Newark, NJ, USA Full list of author information is available at the end of the article
}

health $[2,3]$. In fact, the number of OEF/OIF veterans rating their overall health as fair or poor doubled six months after returning home as compared to their initial postdeployment assessment [2]. This is concerning because lower self-assessed functional health, particularly in the physical domain, has been associated with both greater health care utilization and mortality in veterans of prior conflicts [4-6] and in community samples [7,8].

Although several studies suggest that as time since deployment to OEF/OIF increases so too does the prevalence of poor mental health functioning among US

\section{Biomed Central}


service members, $[2,9,10]$ less attention has been paid to how physical functioning changes over time [11-13]. Importantly, we do not know whether there is a similar trend toward reduced physical function over time since return from deployment from OEF/OIF. Such investigation is especially warranted given that veterans of prior conflicts generally have worse health functioning than the general U.S. population, [5,14] with the largest disparity observed in the physical domain [6]. Moreover, a worsening of physical functioning over time could lead to long term disability and have numerous public health implications (e.g., greater health care utilization and mortality) that would be especially problematic for this relatively young, working age population.

Therefore, the purpose of this study is to examine physical health in OEF/OIF veterans as a function of time since deployment using data from OEF/OIF veterans seen in a post-deployment health clinic. We also examined data from a military community sample as a comparison group to enhance generalizability. This sample participated in a longitudinal, prospective cohort study of OEF/OIF veterans who were followed from predeployment to one year after return from deployment. Because of the strong link between Posttraumatic Stress Disorder (PTSD) and health as well as its high prevalence among OEF/OIF veterans $[15,16]$, we included PTSD in our analysis predicting post-deployment health functioning. Additionally, using data from both clinical (i.e., treatment-seeking) and community samples afforded us the ability to address the concern that our findings were specific only to a treatment-seeking sample. Moreover, if we were to find similar effects across these two different samples, it would suggest a more generalizable impact of military service and thus better inform the public health community.

\section{Methods}

Study design, sample and data extraction (cross-sectional clinical sample)

Data from 679 OEF/OIF veterans clinically evaluated (June 2004 - October 2010) at a post-deployment health clinic (New Jersey War Related Illness and Injury Study Center) were examined retrospectively with approval from the Institutional Review Board at the VA New Jersey Healthcare System and in accordance with the Helsinki Declaration. We stratified our sample into groups by time post-deployment which was computed as the difference between the veterans' clinical evaluation date and return from deployment date. This resulted in the following four groups: (1Yr) $0-365$ days; (2Yr) $366-730$ days; (3Yr) 731 - 1095 days; and $(4 \mathrm{Yr}+)>1095$ days. Distribution by gender was similar between groups with women accounting for approximately $14 \%$ of the total sample (See Table 1 for demographic characteristics).
Veterans clinically evaluated at our post-deployment health clinic typically come for a one-time comprehensive medical evaluation, during which they complete an intake packet which is entered into a database for scoring and evaluation. We abstracted from the veterans' clinical evaluation records the following information: demographics, deployment dates, probable diagnosis of PTSD and responses on the Veterans version of the Short Form 36 Health Survey (known as the Veterans RAND or VR-36).

\section{Comparison group (longitudinal military community sample)}

To address the concern that our findings were specific to a clinical sample with data from only one time point, PCS scores from our clinical sample were compared to a sample of 768 healthy Army National Guard and Reserve enlisted soldiers ( $11 \%$ female) who deployed to OEF/OIF and were evaluated pre-deployment and up to 1 year post deployment. PCS scores were available for pre-deployment, immediate post-deployment and approximately one year (+/- 4 months) after return from deployment. All participants provided informed consent and study procedures were approved by three institutional review boards (VA New Jersey Healthcare System, G.V. (Sonny) Montgomery VA Medical Center, and the Walter Reed Army Medical Center Department of Clinical Investigation).

\section{Measured variables}

For both samples we had the same measures of physical function and PTSD symptoms. From the VR-36, we computed the PCS score to provide an overall measure of physical health-related functioning which was the primary outcome variable. PCS scores are standardized from published results of the US population to a mean of 50 and standard deviation of 10, with higher scores reflecting better health [17-20]. To assess which facets of physical function were most important to overall physical function in this sample, we also assessed four subscales that contribute to the PCS: physical functioning (i.e., the presence and extent of physical limitations), role-physical (i.e., the extent to which one can physically engage in their work or other activities), bodily pain (i.e., intensity and impact of pain) and general health (i.e., rating of health) [21-23].

The Posttraumatic Stress Disorder Checklist-Civilian version (PCL-C) was used to indicate the presence of posttraumatic stress symptoms. The 17 items of the checklist correspond to the diagnostic symptoms of PTSD and the measure demonstrates good psychometric properties in veterans when a score of 50 or more is used to define likely presence of PTSD [24]. For consistency with prior reports from the OEF/OIF population, [25] we chose to additionally require that the Diagnostic and Statistical Manual of Mental Disorders (DSM) IV criteria of one intrusion (e.g., recurrent and distressing recollections, 
Table 1 Demographic characteristics of cross-sectional clinical veteran sample

\begin{tabular}{|c|c|c|c|c|c|}
\hline & \multicolumn{4}{|c|}{ Cross-sectional clinical sample } & \multirow{2}{*}{$\frac{\text { Military community sample }}{n=768}$} \\
\hline & $1 \mathrm{Yr}(n=253)$ & $2 \operatorname{Yr}(n=162)$ & $3 \operatorname{Yr}(n=106)$ & $4 Y r+(n=157)$ & \\
\hline \multicolumn{6}{|l|}{ Gender (\%) } \\
\hline $\mathrm{F}=$ Female & F: $13.0 \%$ & F: $12.9 \%$ & F: $12.3 \%$ & F: $16.6 \%$ & $F: 10.8 \%$ \\
\hline$M=$ Male & M: $87.0 \%$ & M: $87.1 \%$ & M: $87.7 \%$ & M: $83.4 \%$ & M: $89.2 \%$ \\
\hline Age (mean \pm SD) & $32.5 \pm 9.8$ & $32.0 \pm 9.6$ & $32.0 \pm 10.3$ & $34.8 \pm 9.7$ & $28.0 \pm 8.3$ \\
\hline \multicolumn{6}{|l|}{ Military Component (\%) } \\
\hline Active Duty & $25.3 \%$ & $42.9 \%$ & $54.4 \%$ & $48.4 \%$ & - \\
\hline Reserve/National Guard & $74.7 \%$ & $57.1 \%$ & $45.6 \%$ & $51.6 \%$ & $100 \%$ \\
\hline \multicolumn{6}{|l|}{ Military Branch (\%) } \\
\hline Navy & $6.3 \%$ & $5.5 \%$ & $8.5 \%$ & $13.4 \%$ & - \\
\hline Air Force & $1.6 \%$ & $4.3 \%$ & $5.7 \%$ & $10.8 \%$ & - \\
\hline Marine Corps & $15.8 \%$ & $24.5 \%$ & $29.2 \%$ & $17.8 \%$ & - \\
\hline Army & $75.9 \%$ & $65.6 \%$ & $55.7 \%$ & $56.7 \%$ & $100 \%$ \\
\hline Coast Guard & - & - & - & $1.3 \%$ & - \\
\hline Probable PTSD (\%) & $29.8 \%$ & $31.3 \%$ & $45.8 \%$ & $46.6 \%$ & - \\
\hline \multirow[t]{3}{*}{ Physical Component Summary score } & $46.5 \pm 9.6$ & $45.9 \pm 10.9$ & $44.5 \pm 9.1$ & $42.3 \pm 11.8$ & Pre: $55.5 \pm 5.2$ \\
\hline & & & & & 0 Post: $53.2 \pm 7.3$ \\
\hline & & & & & 1yr Post: $52.2 \pm 8.6$ \\
\hline \multirow[t]{3}{*}{ Physical Function subscale } & $46.5 \pm 10.1$ & $45.6 \pm 10.7$ & $43.9 \pm 10.2$ & $41.8 \pm 11.8$ & Pre: $52.4 \pm 7.4$ \\
\hline & & & & & 0 Post: $49.4 \pm 8.3$ \\
\hline & & & & & 1 yr Post: $48.5 \pm 9.8$ \\
\hline \multirow[t]{3}{*}{ Role Physical subscale } & $45.8 \pm 10.8$ & $45.3 \pm 12.2$ & $41.1 \pm 12.9$ & $40.2 \pm 13.1$ & Pre: $54.6 \pm 7.3$ \\
\hline & & & & & 0 Post: $50.3 \pm 9.1$ \\
\hline & & & & & 1 yr Post: $49.6 \pm 9.8$ \\
\hline \multirow[t]{3}{*}{ Bodily Pain subscale } & $42.4 \pm 10.8$ & $42.5 \pm 11.5$ & $41.1 \pm 11.2$ & $38.8 \pm 11.1$ & Pre: $55.3 \pm 3.9$ \\
\hline & & & & & 0 Post: $53.3 \pm 6.7$ \\
\hline & & & & & 1 yr Post: $51.8 \pm 8.9$ \\
\hline \multirow[t]{3}{*}{ General Health subscale } & $43.2 \pm 10.7$ & $41.9 \pm 11.1$ & $39.7 \pm 10.4$ & $38.7 \pm 11.9$ & Pre: $53.2 \pm 5.9$ \\
\hline & & & & & 0 Post: $52.4 \pm 6.8$ \\
\hline & & & & & 1 yr Post: $50.5 \pm 9.2$ \\
\hline
\end{tabular}

flashbacks or dreams about the event), three avoidance (e.g., emotional numbing, avoiding reminders, amnesia for the event) and two hyperarousal symptoms (e.g., hypervigilance, hyperstartle, concentration problems) were also present at the "moderately" or higher level. These two requirements (e.g., PCL-C $\geq 50$ and DSM IV criteria) were used to define probable PTSD.

\section{Statistical analysis}

For our clinical sample, the PCS and the four physical health subscales of the VR-36 were analyzed separately via ANCOVA (covariates of probable PTSD, age, gender, and the combination of PTSD, age and gender) with planned linear polynomial contrasts to assess the effect of time between return from deployment and visit to our clinic. Rates of probable PTSD, age and gender were compared between groups using a chi-square test or one-way ANOVA with Tukey post-hoc comparisons, respectively. A 5\% alpha level (two-tailed) was considered statistically significant.

For our longitudinal military community sample, PCS scores were compared using a mixed model analysis. To handle missing data, we applied the method of multiple imputation [26]. Per Graham [27,28], we created 40 imputed datasets using IVEWare [29] and imputed results were combined using SAS MIANALYZE procedure (SAS v9.1). Demographic variables, including education (as a proxy for socioeconomic status), age and gender, as well as data pertaining to PCS variables collected at all waves were used to generate the imputed datasets. However, multiple imputation was not performed for the clinical sample where less than $2.5 \%$ of data were missing for any variable of interest. Bonferonni correction was applied for multiple tests at a 5\% alpha level (one-tailed). 


\section{Results}

Physical functioning in OEF/OIF veterans seeking care post-deployment (cross-sectional clinical sample)

Mean scores ( \pm standard deviation) for the PCS and four physical health subscales are presented in Table 1. A higher proportion of individuals meeting criteria for probable PTSD occurred in the group seen later after return from deployment (Table 1). Specifically, probable PTSD was more likely in those evaluated at $3 \mathrm{Yr}$ and $4 \mathrm{Yr}+$ after return from deployment in comparison to those evaluated at $1 \mathrm{Yr}\left(1 \mathrm{Yr}\right.$ vs. $4 \mathrm{Yr}+\mathrm{X}^{2}(1)=12.2, \mathrm{p}<0.001$; 1 Yr vs. 3 Yr: $\left.\chi^{2}(1)=6.9, p<0.01\right)$. Gender was similar across groups $(\mathrm{F}(3,678)=0.70, \mathrm{p}=0.69)$, but age was significantly different $(\mathrm{F}(3,678)=2.92, \mathrm{p}=0.03)$. However, Tukey post-hoc comparisons revealed no significant between-group differences.

PCS scores were significantly lower as the time between return from deployment and the visit to our clinic increases after separately controlling for the effects of PTSD $(p=0.02)$, age $(p=0.003)$ or gender $(p=0.001)$, but was not significant after accounting for all three covariates $(\mathrm{p}=0.08)$. Further, both the physical functioning and role-physical subscale scores declined over time ( $\mathrm{p}=0.03$ and $\mathrm{p}=0.02$, respectively) even after adjusting for PTSD, age and gender. Scores for bodily pain also were lower over time after adjusting for age $(p=0.01)$ and gender $(\mathrm{p}=0.002)$, but not probable PTSD $(\mathrm{p}=0.12)$ or the combination $(p=0.31)$. General health was significantly lower as a function of time since deployment after adjusting for probable PTSD ( $p=0.03)$, age $(p=0.001)$ or gender $(\mathrm{p}<0.001)$, and showed a trend when the combination of covariates were included in the model $(\mathrm{p}=0.07)$. A summary of the F-test for the effect of time between deployment and clinic visit using ANCOVA are presented in Table 2. Figure 1 (raw values) illustrates average PCS scores for each year which are similar and in some cases lower than published disease-specific norms (Figure 2) [23].

Analyses were also performed using a more liberal PCL-C cut-off of 25 or more, per recommendations from the Department of Veterans Affairs National
Center for PTSD for maximizing detection of possible PTSD cases (http://www.ptsd.va.gov/professional/pages/ assessments/ptsd-checklist.asp). All significant differences reported above with a PCL-C of $\geq 50$ were also observed using a cut-off of $\geq 25$ (data not presented).

\section{Physical functioning in OEF/OIF veterans (longitudinal military community sample)}

In our comparison longitudinal military community sample of Army National Guard and Reserve enlisted soldiers, predeployment PCS scores (55.5 \pm 5.2$)$ were significantly lower immediately post-deployment $(53.2 \pm 7.3 ; t(227)=5.88$, $\mathrm{p}<0.001)$, and lower still approximately one year later $(52.3 \pm 8.6 ; t(135)=7.67), \mathrm{p}<0.001)$. Further, PCS scores one-year following return from deployment were lower than immediately post-deployment $(t(107)=2.27$, $\mathrm{p}=0.01)$. Differences in PCS scores of $2-5$ points are typically considered clinically significant, [23] and are notable given that these individuals have higher than normal pre-deployment PCS scores (i.e., $1 / 2$ of a standard deviation above the mean for the population).

\section{Discussion}

Veterans evaluated at our post-deployment health clinic endorsed physical health-related functioning that is substantially worse than that of the general US population (Figure 1) and indicative of impaired physical functioning irrespective of time post-deployment (Figure 2). However, for those in our clinical sample the longer after the return from deployment that the veteran attended the clinic, the worse his/her physical function. PCS scores remained low (i.e., poor physical function) even after accounting for comorbidity with probable PTSD, suggesting that physical health-related functioning may be an important problem regardless of PTSD status. Similarly, two subscales that comprise the PCS score (i.e., physical functioning and role-physical functioning) also indicated that the longer after return from deployment that Veterans were seen in our clinic, the lower their physical health even with adjustment for PTSD, age and

Table 2 Analysis of Covariance (ANCOVA) summary table

\begin{tabular}{|c|c|c|c|c|c|}
\hline Variable & Covariate: PTSD & Covariate: Age & Covariate: Gender & $\begin{array}{l}\text { Covariates: PTSD + } \\
\text { Age + Gender }\end{array}$ & $\begin{array}{l}\text { Linear contrast results } \\
\text { (PTSD; Age; Gender; } \\
\text { PTSD + Age + Gender) }\end{array}$ \\
\hline PCS & $F(3,608)=3.3, p=0.02$ & $F(3,608)=5.9, p<0.01$ & $F(3,643)=5.9, p<0.01$ & $F(3,604)=2.2, p=0.08$ & $\begin{array}{l}p<0.001 ; p<0.01 \\
p<0.001 ; p=0.01\end{array}$ \\
\hline Physical Function & $F(3,624)=4.1, p=0.01$ & $F(3,624)=4.7, p<0.01$ & $F(3,661)=6.8, p<0.001$ & $F(3,622)=2.9, p=0.03$ & $\begin{array}{l}p<0.01 ; p<0.001 \\
p<0.001 ; p=0.03\end{array}$ \\
\hline Role Physical & $F(3,620)=4.2, p<0.01$ & $F(3,620)=8.4, p<0.001$ & $F(3,657)=9.4, p<0.001$ & $F(3,618)=3.5, p=0.02$ & $\begin{array}{c}p<0.001 ; p<0.001 ; \\
p<0.001 ; p<0.01\end{array}$ \\
\hline Bodily Pain & $F(3,628)=1.9, p=0.12$ & $F(3,628)=3.9, p=0.01$ & $F(3,663)=4.8, p<0.01$ & $F(3,624)=1.2, p=0.31$ & $\begin{array}{l}p=0.05 ; p<0.01 \\
p<0.01 ; p=0.13\end{array}$ \\
\hline General Health & $F(3,623)=2.9, p=0.03$ & $F(3,623)=5.7, p<0.01$ & $F(3,660)=6.3, p<0.001$ & $F(3,621)=2.3, p=0.07$ & $\begin{array}{l}p<0.01 ; p<0.001 \\
p<0.001 ; p=0.01\end{array}$ \\
\hline
\end{tabular}




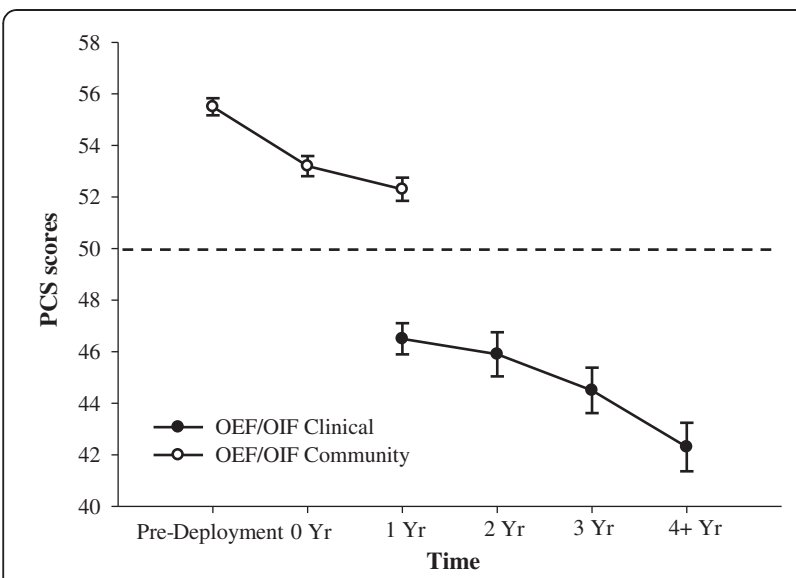

Figure 1 Physical Component Summary (PCS) scores.

Comparison of PCS scores obtained in our clinical (OEF/OIF Clinical) veterans with those from our military community sample (OEF/OIF

Community). For the community sample, ' 0 yr' represents the mean PCS score obtained immediately post-deployment. Note that higher PCS scores reflect better physical health, and the dashed line represents the U.S. general population average.

gender. Together these findings suggest that given the average age of our sample (i.e., 32 years), it is critically important to plan carefully for what could be substantial, and long-term future health care needs for this cohort of veterans.

A potential limitation of the cross-sectional clinical sample is that PCS scores indicating poor physical function may simply mean that veterans wait to be seen at our post-deployment health clinic until they are sufficiently symptomatic. Since we do not have pre- or early postdeployment data on this clinical sample it is impossible to say if the service members have worsened over time, if their condition has always been poor, or if those who were seen further from their deployment date simply had a higher threshold for seeking care in the face of symptoms. However, the PCS scores in our military community sample of individuals deploying to OEF/OIF obtained before, immediately after and about one-year post-deployment also demonstrated a decrease in PCS scores over time with lower scores post-deployment than pre-deployment despite the fact that the latest post-deployment data was obtained only one year after return (Figure 1). Additionally, we could confirm that on average, this sample was physically healthier than the general US population before deploying. Although a decrease in PCS scores from predeployment to immediately post-deployment may be expected due to the physical rigors of the deployment, it is concerning that physical function not only did not improve by 1 year post-deployment, but continued to decline. In fact, PCS scores obtained at 1-year were significantly lower than those obtained immediately postdeployment. Because PCL scores were not available for all time points in this longitudinal sample, we did not control for PTSD in this analysis. Regardless of the factors that may be affecting physical health functioning, such as the presence of probable PTSD, when compared to pre-deployment, PCS scores of veterans one year after deployment were more than three points lower, a difference that in prior literature has been considered clinically significant [23]. Equally concerning is that from immediately afterdeployment to the one year follow-up, these individuals (mean age $=28$ years) demonstrated an approximately 0.9 point decrease in PCS. Thus, even in a military community sample group of veterans over just the first year after return we observed a decrease in physical function from pre- to one-year post-deployment (i.e., over approximately 2 years) that appears to be declining at a faster rate than normal aging. For example, this magnitude

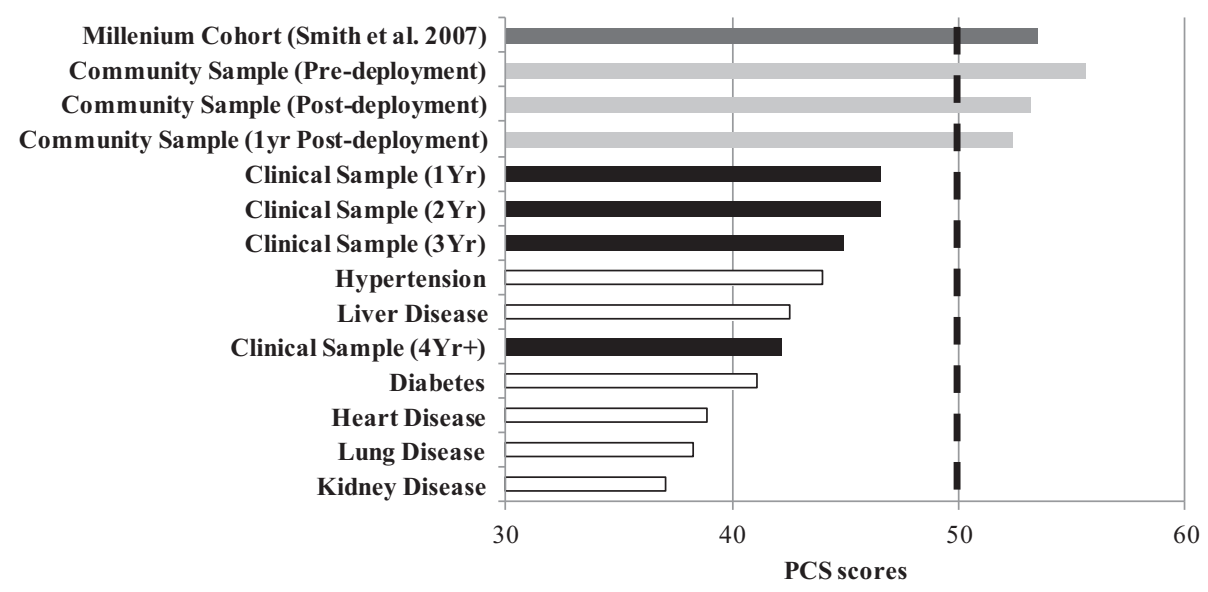

Figure 2 Comparison of PCS scores with other populations. Comparison of observed PCS scores from our cross-sectional clinical sample of OEF/OIF veterans and military community sample with norms for various disease states [23] as well as pre-deployment values from the Millennium Cohort Study [1]. Note that the dashed vertical line represents the U.S. population average. 
of decline is equivalent to approximately half the decrease seen in population norms from the mid-thirties to midforties [23]. That a decline in physical health-related functioning is also present in a military community sample reinforces our observations in those veterans seeking treatment and illustrates a potential robust trend towards declining physical health in OEF/OIF veterans.

In our clinical sample, the longer the duration between return from deployment and their visit to our clinic, the worse the Veteran's physical health. Irrespective of the length between return from deployment and visit to our clinic, their rating of physical health is worse than that of the general U.S. population (Figure 1). Moreover, veterans $4 \mathrm{Yr}+$ after a combat deployment report physical health that is worse than individuals with hypertension or liver disease, and their PCS scores begin to approach those of individuals with more severe chronic diseases (Figure 2) [23]. This is alarming given that PCS scores from over 77,000 service members in the Millennium Cohort Study exceeded the US general population norm (95\% CI: 53.3 - 53.4) [1] as did the PCS scores from our longitudinal military community sample at pre-deployment (Figure 1). Further, previous work in veteran and non-veteran community samples, even for those who are middle aged (i.e., Miilunpalo et al. [8]), has found that decreases in physical function (PCS) are related to increased risk of both hospitalization and mortality. For example, in a sample of mostly older veterans, a 10-point decrease in PCS in veterans is associated with an age-adjusted 1.4 - 1.8 fold increased risk of hospitalization and a $2.0-2.6$ fold increased risk of mortality $[15,30]$. A decrement of $5-10$ points significantly increased the risk of hospitalization (OR 1.13) and mortality (OR 1.14) [30]. Considering that we found decrements in PCS ranging from 0.9 (immediately post to one-year) in our longitudinal military community sample and 4.2 ( $1 \mathrm{Yr}$ to $4 \mathrm{yr}+$ ) in our cross-sectional sample, it suggests that continued declines like this in these relatively young veterans could confer a future increased risk of hospitalization and mortality. These preliminary data highlight the need for further longitudinal work beyond one-year post-deployment to determine the extent and mechanisms underlying declines in physical function in veterans seeking and not seeking care.

A strength of this study was our ability to compare data from our cross-sectional clinical sample to data from a longitudinal study of community military personnel. We were however, not able to control for PTSD in the community sample. Additionally, we were limited by only having self-report data and not assessing factors contributing to poorer physical health post-deployment such as physical ailments or injuries of particular relevance to this cohort of veterans, e.g. respiratory-related illnesses and mild traumatic brain injury. Future studies should continue to explore factors that contribute to declining physical function after deployment.

\section{Conclusions}

In summary, our observed PCS scores in OEF/OIF veterans were lower with increasing time between return from deployment and the visit to our clinic. These data are important because poorer physical function has been associated with greater health care utilization and increased mortality in both veterans and civilians [6,7]. Though poor physical health may be attributable to a variety of factors, these data should serve as a critical warning as these veterans are self-reporting poor physical health well beyond what is expected for their ages. This work highlights the need for thorough post-deployment screening and early intervention to minimize the decline in physical health and any associated increases in disability and health care utilization that may result if physical dysfunction is not addressed in a timely way for returning $\mathrm{OEF} /$ OIF veterans.

\section{Abbreviations}

OEF: Operation Enduring Freedom; OIF: Operation Iraqi Freedom; PCS: Physical Component Summary Score; PTSD: Posttraumatic Stress Disorder; PCL-C: Posttraumatic Stress Disorder Checklist-Civilian version; VR36: Veterans version of the Short Form 36 Health Survey; ANCOVA: Analysis of Covariance.

\section{Competing interests}

The authors declare that they have no competing interests.

\section{Authors' contributions}

All investigators report no conflicts of interest and contributed to the study concept and provided critical revisions to the manuscript. MF, JS, and KQ drafted the manuscript and performed the background literature search. Data analyses were performed by MF and SL, with input from all investigators, and data were provided by $K Q, H C$, and $L M$. All authors read and approved the final manuscript.

\section{Acknowledgements}

This study was supported by VA HSR\&D IIR 02-296 (to Karen Quigley, PhD) with additional support from the New Jersey War Related IIIness and Injury Study Center (Gudrun Lange, PhD, Director), the East Orange Research Enhancement Award Program (Len Pogach, MD, Director) and the Department of Defense Deployment Health Clinical Center (Charles C. Engel, MD, Director). This material is also the result of work supported with resources and the use of facilities at the VA New Jersey Health Care System. We also gratefully acknowledge the efforts of Pauline McManus, RN, Melissa Blatt, MSN, Liliana Almeida, MS, and the HEROES Team in the collection and preparation of data. The views expressed in this article are those of the authors and do not necessarily represent the views of the Department of Veterans Affairs.

\section{Author details}

'War Related IIIness and Injury Study Center, Department of Veterans Affairs New Jersey Health Care System, 385 Tremont Ave, East Orange, NJ, USA. ${ }^{2}$ Department of Physical Medicine and Rehabilitation, New Jersey Medical School - University of Medicine and Dentistry of New Jersey, Newark, NJ, USA. ${ }^{3}$ Veterans Biomedical Research Institute, Department of Veterans Affairs New Jersey Health Care System, East Orange, NJ, USA. ${ }^{4}$ Department of Pharmacology \& Physiology, New Jersey Medical School - University of Medicine and Dentistry of New Jersey, Newark, NJ, USA. ${ }^{5}$ Department of Neurology, Stroke Division, Brigham and Women's Hospital, Boston, MA, USA. 'Harvard Medical School, Boston, MA, USA. ${ }^{7}$ Department of Electrical \& Electronic Engineering, National 
University of Ireland Galway, Galway, Ireland. ${ }^{8}$ Department of Psychiatry, New Jersey Medical School-University of Medicine and Dentistry of New Jersey, Boston, MA, USA. ${ }^{9}$ School of Public Health, University of Medicine and Dentistry of New Jersey, Piscataway, NJ, USA. ${ }^{10}$ Center for Health Quality, Outcomes, and Economic Research, Edith Nourse Rogers (Bedford) VA Memorial Hospital, Bedford, MA, USA. " ${ }^{11}$ Department of Psychology, Northeastern University, Boston, MA, USA

Received: 4 June 2012 Accepted: 19 December 2012

Published: 28 December 2012

\section{References}

1. Smith TC, Zamorski M, Smith B, Riddle JR, Leardmann CA, Wells TS, et al: The physical and mental health of a large military cohort: baseline functional health status of the Millennium Cohort. BMC Publ Health 2007, 7:340.

2. Milliken CS, Auchterlonie $J$, Hoge CW: Longitudinal assessment of mental health problems among active and reserve component soldiers returning from the Iraq War. JAMA 2007, 298:2141-2148.

3. Sayer NA, Noorbaloochi S, Frazier P, Carlson K, Gravely A, Murdoch M: Reintegration problems and treatment interests among Iraq and Afghanistan combat veterans receiving VA medical care. Psychiatr Serv 2010, 61:589-597.

4. DeSalvo KB, Fan VS, McDonell MB, Fihn SD: Predicting mortality and healthcare utilization with a single question. Health Serv Res 2005, 40:1234-1246

5. Kazis LE, Miller DR, Clark J, Skinner K, Lee A, Rogers W, et al: Health-related quality of life in patients served by the department of veterans affairs: results from the veterans health study. Arch Intern Med 1998, 158:626-632.

6. Singh JA, Borowsky SJ, Nugent S, Murdoch M, Zhao Y, Nelson DB, et al: Health-related quality of life, functional impairment, and healthcare utilization by veterans: Veterans' Quality of Life Study. J Am Geriatr Soc 2005, 53:108-113.

7. Idler EL, Benyamini Y: Self-rated health and mortality: a review of twentyseven community studies. J Health Soc Behav 1997, 38:21-37.

8. Miilunpalo S, Vuori I, Oja P, Pasanen M, Urponen H: Self-rated health status as a health measure: the predictive value of self-reported health status on the use of physician services and on mortality in the working-age population. J Clin Epidemiol 1997, 50:517-528.

9. Seal KH, Metzler TJ, Gima KS, Bertenthal D, Maquen S, Marmar CR: Trends and risk factors for mental health diagnoses among Iraq and Afghanistan veterans using Department of Veterans Affairs health care, 2002-2008. Am J Public Health 2009, 99:1651-1658.

10. Thomas JL, Wilk JE, Riviere LA, McGurk D, Castro CA, Hoge CW: Prevalence of mental health problems and functional impairment among active component and National Guard soldiers 3 and 12 months following combat in Iraq. Arch Gen Psychiatry 2010, 67:614-623.

11. Helmer DA, Chandler HK, Quigley KS, Blatt M, Teichman R, Lange G: Chronic widespread pain, mental health, and physical role function in OEF/OIF veterans. Pain Med 2009, 10:1174-1182.

12. Jakupcak M, Luterek J, Hunt S, Conybeare D, McFall M: Posttraumatic stress and its relationship to physical health functioning in a sample of Iraq and Afghanistan War veterans seeking postdeployment VA health care. J Nerv Ment Dis 2008, 196:425-428.

13. Kline A, Falca-Dodson M, Sussner B, Ciccone DS, Chandler H, Callahan L, et al: Effects of repeated deployment to Iraq and Afghanistan on the health of New Jersey Army National Guard troops: implications for military readiness. Am J Public Health 2010, 100:276-283.

14. Agha Z, Lofgren RP, VanRuiswyk JV, Layde PM: Are patients at Veterans Affairs medical centers sicker? a comparative analysis of health status and medical resource use. Arch Intern Med 2000, 160:3252-3257.

15. Barrett DH, Doebbeling CC, Schwartz DA, Voelker MD, Falter KH, Woolson RF, et al: Posttraumatic stress disorder and self-reported physical health status among U.S. Military personnel serving during the Gulf War period: a population-based study. Psychosomatics 2002, 43:195-205.

16. Frayne SM, Chiu WY, lqbal S, Berg EA, Laungani KJ, Cronkite RC, et al: Medical care needs of returning veterans with PTSD: their other burden. J Gen Intern Med 2011, 26:33-39.

17. Jones D, Kazis L, Lee A, Rogers W, Skinner K, Cassar L, et al: Health status assessments using the veterans SF-12 and SF-36: methods for evaluating outcomes in the Veterans Health Administration. J Ambul Care Manage 2001, 24:68-86.
18. Kazis LE, Austin FL, Spiro A, Miller DR, Rogers WRXS, Zhang M, Kazis LE, Austin FL, Spiro A, Miller DR, Rogers WRXS, Zhang M: HOSNA Comparison Project. Health Outcomes Technology Program 2002: U.S. Department of Health \& Human Services; 2002. http://www.cms.hhs.gov/surveys/hos/download/ HOS_VA_Comparison_Project_Part2.pdf Accessed online: 3-31-2011.

19. Perlin JB, Kazis LE, Skinner K, Ren XS, Lee A, Rogers WH, et al: Health Status and Outcomes of Veterans: 1999 Large Health Survey of Veterans Executive Report. Washington, DC, Department of Veterans Affairs, Veterans Health Administration: Report: Office of Quality and Performance; 2000.

20. Ware JE Jr, Sherbourne CD: The MOS 36-item short-form health survey (SF-36). I. Conceptual framework and item selection. Med Care 1992 30:473-483.

21. Kazis LE: The veterans SF-36 health status questionnaire: development and application in the Veterans Health Administration. Med Outcomes Trust Monit 2000, 5:1-14

22. Kazis LE, Skinner KM, Ren XS, Perlin J: Health status and outcomes of veterans: Physical and mental component summary scores. Veterans SF-36, 1999 large health survey of veteran enrollees. Washington (DC), Department of Veterans Affairs, Veterans Health Administration, Office of Quality and Performance: Ref Type: Report; 2000.

23. Ware JE, Kosinski M, Bjorner JB, Turner-Bowker DM, Gandek B, Maruish ME: User's Manual for the SF-36v2 Health Survey. 2nd edition. Lincoln, RI: QualityMetric Incorporated; 2007.

24. Weathers FW, Litz B: The PTSD Checklist (PCL): Reliability, validity, and diagnostic utility. Annual Meeting of the International Society for Traumatic Stress Studies. San Antonio, TX: 1993.

25. Hoge CW, McGurk D, Thomas JL, Cox AL, Engel CC, Castro CA: Mild traumatic brain injury in U.S. Soldiers returning from Iraq. N Engl J Med 2008, 358:453-463.

26. Schafer JL: Analysis of incomplete multivariate data. London: Chapman and Hall; 1997

27. Graham JW, Olchowski AE, Gilreath TD: How many imputations are really needed? some practical clarifications of multiple imputation theory. Prev Sci 2007, 8:206-213.

28. Graham JW: Missing data analysis: making it work in the real world. Annu Rev Psychol 2009, 60:549-576.

29. Raghunathan T, Solenberger P, Hoewyk J: IVEware: Imputation and Variance Estimation Software User Guide: Survey Methodology Program; 2002.

30. Fan VS, Au DH, McDonell MB, Finn SD: Intraindividual change in SF-36 in ambulatory clinic primary care patients predicted mortality and hospitalizations. J Clin Epidemiol 2004, 57:277-283.

doi:10.1186/1471-2458-12-1124

Cite this article as: Falvo et al:: A retrospective cohort study of U.S.

service members returning from Afghanistan and Iraq: is physical health worsening over time?. BMC Public Health 2012 12:1124.

\section{Submit your next manuscript to BioMed Central and take full advantage of:}

- Convenient online submission

- Thorough peer review

- No space constraints or color figure charges

- Immediate publication on acceptance

- Inclusion in PubMed, CAS, Scopus and Google Scholar

- Research which is freely available for redistribution 